\section{Jurnal Kimia Sains dan Aplikasi Journal of Scientific and Applied Chemistry}

Journal homepage: http://ejournal.undip.ac.id/index.php/ksa

\title{
Statistical Approach for Water Glass Precursor Preparation from Bamboo Leaf Silica
}

\author{
S Silviana ${ }^{a,},{ }^{*}$, Bakti Jos ${ }^{a}$, Herry Santosa ${ }^{a}$, Siswo Sumardiono ${ }^{a}$ \\ a Department of Chemical Engineering, Faculty of Engineering, Diponegoro University. Jl. Prof. H. Soedarto, S.H., Kampus Tembalang \\ Semarang, Indonesia \\ * Corresponding author:silviana@che.undip.ac.id
}

https://doi.org/10.14710/jksa.22.2.52-57

\section{Article Info}

Article history:

Received: 7 January 2019

Revised: 30 March 2019

Accepted: 30 March 2019

Online: 31 March 2019

Keywords:

bamboo leaf silica, potassium hydroxide, silica aerogel, water glass

\section{Abstract}

The bamboo leaf consists of high silica content. In this study, the bamboo silica was utilized as water glass. Water glass can also be used as eco-friendly precursors for the preparation of silica aerogel. The extraction process of silica from bamboo leaf have been carried out through acid leaching and combustion process at $750^{\circ} \mathrm{C}$ based on thermal gravimetry analysis. This paper is aimed to assess the effect of two types of alkali hydroxide and concentrations producing water glass of bamboo leaf silica. The result was analyzed by using a $2^{2}$-factorial design with six replications. The alkali hydroxide types were sodium hydroxide and potassium hydroxide with a concentration of $4 \mathrm{M}$ and $6 \mathrm{M}$, respectively. The study was executed in several steps, i.e. pre-treatment of bamboo leaf, leaching process, combustion, purification of bamboo leaf silica and synthesis of water glass. The optimum condition of water glass products was obtained at silica concentration of $41.08 \mathrm{ppm}$ and density of $1.23 \mathrm{~g} / \mathrm{L}$ for potassium hydroxide, while at $40.15 \mathrm{ppm}$ and $1.30 \mathrm{~g} / \mathrm{L}$ for sodium hydroxide. ANOVA analysis resulted in a significant effect for type of hydroxide and concentration releasing model for silica concentration response. This study also characterized the silica structure and composition by instrumentation analysis for silica solid obtained from optimum water glass condition with potassium hydroxide. It can be denoted the physical behavior of silica solid from water glass by potassium hydroxide did not differ from previous research of water glass by sodium hydroxide.

\section{Introduction}

Bamboo leaf is a promising natural source regard with the content of bio-silica or silicon dioxide or silica $\left(\mathrm{SiO}_{2}\right)$ equal to $78.71 \mathrm{~g} / \mathrm{kg}$ of dried bamboo leaf [1]. The silica content is influenced by the bamboo type and region for bamboo growth. Silica of bamboo leaf has been used as a great deal of natural silica source for preparation of water glass due to the high content of silica. It is considered that the silica content of bamboo leaf or bamboo leaf ash (BLA) is higher than that of rice husk [2]. One of an intermediate product from silica can be made for water glass as a precursor of silica aerogel. Silica aerogel in the future can be used as an adsorbent, heat insulator, supercapacitor or supporting material in the catalyst [2]. Currently, the application of water glass as a precursor or sodium orthosilicate $\left(\mathrm{Na}_{4} \mathrm{SiO}_{4}\right)$ from the bamboo leaf is the more environmentally friendly method to produce silica aerogel than that of a silicon alkoxide compound such as tetraethylorthosilicate (TEOS) [3] and tetramethylorthosilicate (TMOS) as a precursor. Unfortunately, TEOS/TMOS are expensive and have a high hazard level causing blindness and unfriendly for the environment [4]. The extraction process of silica from bamboo leaf have been carried out through acid leaching and combustion. Then, common chemicals employed in the conversion of silica to water glass uses sodium hydroxide [5], while potassium hydroxide has been used in this paper to compare the result. Bamboo leaf treatment releasing water glass consisted of washing, leaching with hydrochloric acid, calcination, mixing with alkali hydroxide, and filtering. In the end, the solution was filtered to remove undissolved purified BLA. All these steps referred to previous research $[5,6]$. In this paper, it observes statistical approaching for the effect of alkali hydroxide type and its concentration on the quality of water glass produced denoted by concentration and density. Afterward, the study further prepared silica from 
water glass produced from the optimum condition. The silica formed was analyzed by instrument analysis such as crystalline analysis, surface topography, fracture behavior and elements content analysis.

\section{Materials and Methods}

\subsection{Materials}

Bamboo leaf was obtained from bamboo petung (Dendrocalamus asper) delivered from Sragen. Hydrochloric acid ( $\mathrm{HCl}$ ) (Mallinckrodt, 37\%), sodium hydroxide $(\mathrm{NaOH})$ (Merck, 99\%) and potassium hydroxide (KOH) (Merck, 99\%) were purchased from the supplier without any purification treatments. Commercial silica gel was purchased from a chemical store in Semarang. The research employed several types of equipment, such as planetary ball mill to reduce the size of silica powder, ultrasonic processor FS-250N to homogenize sodium silicate and spectrophotometry UV Mini-1240 Shimadzu to analyze the water glass. A DTG60 Thermal Gravimetry Analyzer instrument have been used to analyze decomposition temperature of the bamboo leaf with operation temperature at $30-1000^{\circ} \mathrm{C}$, temperature rate of $10^{\circ} \mathrm{C} / \mathrm{min}$, and flow rate of nitrogen of $30 \mathrm{~mL} / \mathrm{min}$. The crystalline analysis used Xaltical X-ray Diffraction (XRD) tool, Xpert Pro (Utrecht, Netherland) with $40 \mathrm{kV}$ and $30 \mathrm{~mA}$ currents. Results from XRD were recorded at $2 \theta$ angles in the $10^{\circ}$ to $90^{\circ}$ range. Scanning Electron Microscope (SEM) Inspect S50 Energy-Disperse $\mathrm{X}$-ray (SEM EDX, FEI) was required to confirm for surface topography, fracture, and elements content.

\subsection{Water Glass Precursor Preparation}

In the beginning, the bamboo leaf was washed with hot water many times to remove solid impurities prior to making drying. Subsequently, the bamboo leaf was grounded into to reduce size. Next, the sized bamboo leaf was soaked with $\mathrm{HCl} 1 \mathrm{~N}$ for 2 hours purposed to remove impurities by leaching. Afterward, the leached bamboo leaf can be calcined in furnace to remove organic compound and to release bamboo leaf ash (BLA). Then, purified BLA have been mixed with alkali hydroxide. Shortly after mixing with alkali, the solution was filtered to remain dissolved purified BLA [5]. The experiment was designed by using Design Expert 8.0.6 described in Table 1. The experiment design used two factors, i.e. alkali type with $\mathrm{KOH}$ and $\mathrm{NaOH}$, the concentration of $6 \mathrm{M}$ and $4 \mathrm{M}$ for $\mathrm{KOH}$ and $\mathrm{NaOH}$, respectively. Due to the full factorial design with two variables, the experiment design used upper and lower level in each variable. Optimum consideration referred to statistical analysis further used to release silica from water glass. Afterward, water glass was introduced acid by $\mathrm{HCl} 1 \mathrm{~N}$ to reduce impurities by dissolving into an acid solution and obtain the silica solid. Then, the solution was introduced filtration to separate silica solid. The silica solid was dried under a temperature of $105^{\circ} \mathrm{C}$ until constant weight.

Table 1. Experiment design of design factorial $2^{2}$

\begin{tabular}{ccc}
\hline Experiment factor & $\begin{array}{c}\text { Upper } \\
\text { variable }(+)\end{array}$ & $\begin{array}{c}\text { Lower } \\
\text { variable (-) }\end{array}$ \\
\hline Alkali type & $\mathrm{KOH}$ & $\mathrm{NaOH}$ \\
Alkali concentration & $6 \mathrm{M}$ & $4 \mathrm{M}$ \\
\hline
\end{tabular}

\subsection{Characterization}

Bamboo leaf ash was obtained from burning in furnace based on decomposition temperature obtained by TGA analysis. UV-Visible analysis has been introduced to measure appropriate reaction between BLA with alkali hydroxide with several concentrations. The transmittance was measured by a spectrophotometer with wavelength $(\lambda)$ of $351 \mathrm{~nm}$ for silica compound [7]. From the transmittance data, a standard curve of water glass must be attained with the least square method with the highest $\mathrm{R}^{2}$. The concentration-response can be defined by using this least square measured the transmittance by using Spectrophotometer UV Mini-1240 Shimazu. Measuring water glass product density used pycnometer and compared with the density of commercial water glass. Further analysis had been confirmed by using XRD to investigate the silica prepared from the optimum condition of water glass preparation and SEM-EDX to provide elemental identification and quantitative compositional information from silica.

\section{Results and Discussion}

\subsection{Bamboo leaf characterization}

As mention earlier, at the end of BLA preparation was conducted on calcination or thermal process by using furnace at temperature depends on TGA analysis of bamboo leaf. Figure 1 gives information about the temperature when the material is introduced thermally.

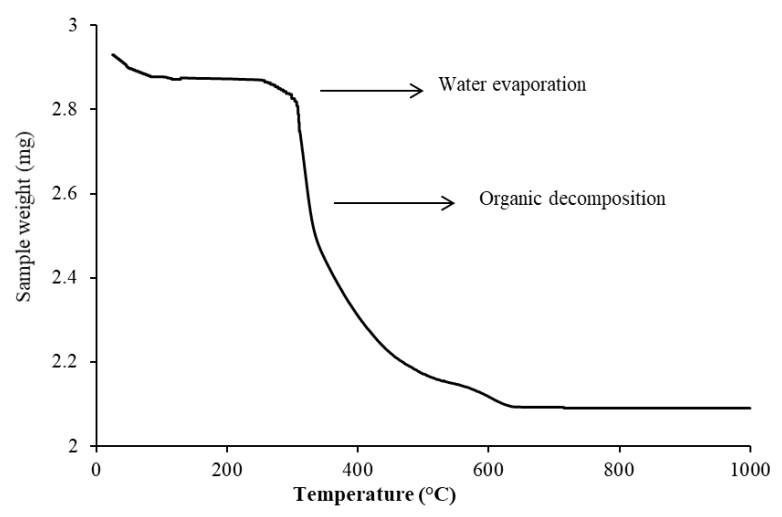

Figure 1. Thermogravimetric analysis of petung bamboo leaf temperature of $30-1000^{\circ} \mathrm{C}$

Fig. 1 represents that at the temperature between 30$100^{\circ} \mathrm{C}$ there was a reduction of moisture content [2] at petung bamboo leaf. In the beginning, bamboo leaf consisted of $8 \%$ moisture content. Formerly, the water content of bamboo leaf was reduced in order to avoid inhibition of diffusion during the burning process [5]. At the temperature above $200^{\circ} \mathrm{C}$, the weight of bamboo leaf decreased denoted that decomposition of an organic compound was started up to a temperature of $600^{\circ} \mathrm{C}$. The organic compound in the bamboo leaf was perfectly decomposed shown by the constant weight of the bamboo leaf ash at $700^{\circ} \mathrm{C}$, so in this research, the burning process of the bamboo leaf was executed at a temperature of $750^{\circ} \mathrm{C}$ produced $20 \%$ of the initial weight of bamboo leaf. The bamboo leaf ash, in general, is mostly containing silica $\left(\mathrm{SiO}_{2}\right)$ with some impurities. Leaching process by acid leaching with $\mathrm{HCl}$ can help to remove the inorganic impurities which could block in the forming of silica with amorphous structure [3]. In this step of the leaching 
process, the weight of leached bamboo leaf released about $79.03 \%$ from the initial.

\subsection{Concentration Analysis and Density on Water Glass Products}

This study used statistical methods to determine the effect of significant variables on the quality of water glass products referring to the high concentration and proper density. The alkali hydroxide type (A) and alkali hydroxide concentration (B) denoted as independent variables, whereas the response was the water glass concentration analyzed by UV-Vis spectrophotometry and water glass density. The first step, the standard curve was attained at using this least square of $\mathrm{y}=0,0364 \mathrm{x}-$ 0,6488 with $\mathrm{R}^{2}$ of 0.98 . This least square can be used to calculate the concentration of samples $(x)$ by use of absorbance (y). A further step, the research conducted the experiment design with the response of concentration and density presented in Table 2 . The statistical method applied in this research employed factorial design $2^{2}$ with six (6) replications. Replication is used to maintain consistency of the response data, thereby reducing the estimated error or error in research conducted with a minimum of $80 \%$ accuracy of results [7]. Six replications were used in this study resulting in a yield accuracy of $83.1 \%$, while four replications that resulted in the inaccuracy of $63.8 \%$ and five replication results with an accuracy of $75 \%$.

Table 2. Factorial design $2^{2}$ with six replications

\begin{tabular}{|c|c|c|c|c|}
\hline Run & $\begin{array}{c}\text { Factor } \\
\text { A }\end{array}$ & $\begin{array}{c}\text { Factor } \\
\text { B }\end{array}$ & $\begin{array}{l}\text { Concentration } \\
(\mathrm{gr} / \mathrm{L})\end{array}$ & $\begin{array}{c}\text { Density } \\
(\mathrm{gr} / \mathrm{L})\end{array}$ \\
\hline 1 & $\mathrm{KOH}$ & 6 & 26.51 & 1.28 \\
\hline 2 & $\mathrm{NaOH}$ & 4 & 40.29 & 1.27 \\
\hline 3 & $\mathrm{NaOH}$ & 6 & 54.96 & 1.29 \\
\hline 4 & $\mathrm{KOH}$ & 4 & 43.68 & 1.22 \\
\hline 5 & $\mathrm{NaOH}$ & 6 & 39.42 & 1.35 \\
\hline 6 & $\mathrm{NaOH}$ & 6 & 37.49 & 1.31 \\
\hline 7 & $\mathrm{NaOH}$ & 4 & 29.52 & 1.22 \\
\hline 8 & $\mathrm{KOH}$ & 4 & 41.65 & 1.24 \\
\hline 9 & $\mathrm{KOH}$ & 4 & 52.90 & 1.24 \\
\hline 10 & $\mathrm{KOH}$ & 4 & 33.66 & 1.25 \\
\hline 11 & $\mathrm{NaOH}$ & 6 & 35.49 & 1.29 \\
\hline 12 & $\mathrm{KOH}$ & 6 & 22.41 & 1.29 \\
\hline 13 & $\mathrm{KOH}$ & 6 & 26.70 & 1.31 \\
\hline 14 & $\mathrm{NaOH}$ & 4 & 32.42 & 1.26 \\
\hline 15 & $\mathrm{NaOH}$ & 4 & 32.65 & 1.22 \\
\hline 16 & $\mathrm{NaOH}$ & 6 & 43.58 & 1.31 \\
\hline 17 & $\mathrm{KOH}$ & 6 & 27.44 & 1.22 \\
\hline 18 & $\mathrm{NaOH}$ & 6 & 35.58 & 1.29 \\
\hline 19 & $\mathrm{KOH}$ & 4 & 56.54 & 1.25 \\
\hline 20 & $\mathrm{KOH}$ & 6 & 24.07 & 1.29 \\
\hline 21 & $\mathrm{KOH}$ & 6 & 25.79 & 1.27 \\
\hline 22 & $\mathrm{KOH}$ & 4 & 30.45 & 1.22 \\
\hline 23 & $\mathrm{NaOH}$ & 4 & 37.55 & 1.23 \\
\hline 24 & $\mathrm{NaOH}$ & 4 & 35.23 & 1.26 \\
\hline
\end{tabular}

This statistic method generated an equation model using Analysis of Variance (ANOVA). ANOVA was used to know not only of each independent variable effect, the interaction effect between independent variable to response, but also an assessment of the chosen model. The significant of the equation model is attributed if the value of $\mathrm{p}>\mathrm{F}$ is less than 0.05 and the $\mathrm{F}$ value is greater than one [8]. While the appropriate equation model is assessed from the value of $\mathrm{R}^{2}$, adjusted- $\mathrm{R}^{2}$, predicted- $\mathrm{R}^{2}$ and adequate precision where the small difference $(<0.2)$ of each value of $\mathrm{R}^{2}$ with adjusted- $\mathrm{R}^{2}$ and predicted $-\mathrm{R}^{2}$, and the value of adequate precision more than four indicates Model eligible eligibility.

Table 3. Analysis of variance (ANOVA) results for water glass concentration response

\begin{tabular}{ccccccc}
\hline Source & $\begin{array}{c}\text { Sum of } \\
\text { Squares }\end{array}$ & Df & $\begin{array}{c}\text { Mean } \\
\text { square }\end{array}$ & $\begin{array}{c}\text { F- } \\
\text { value }\end{array}$ & $\begin{array}{c}\text { Prob }>\text { Significance } \\
\text { F }\end{array}$ & \\
\hline Model & 0.0009 & 3 & 0.0003 & 16.68 & $<0.0001$ & Significant \\
Alkali type, A & 0.0004 & 1 & 0.0001 & 7.98 & 0.0105 & Significant \\
Concentration, & 0.0002 & 1 & 0.0002 & 9.97 & 0.0050 & Significant \\
$\mathrm{B}$ & & & & & & \\
$\mathrm{AB}$ & 0.0006 & 1 & 0.0006 & 32.08 & $<0.0001$ & Significant \\
$\mathrm{R}^{2}$ & & & & 0.7144 & & \\
Adjusted $\mathrm{R}^{2}$ & & & & 0.6716 & & \\
Predicted $\mathrm{R}^{2}$ & & & & 0.5888 & & \\
Adequate & & & & 8.822 & & \\
precision & & & & & & \\
\hline
\end{tabular}

The results of ANOVA on the water glass concentration analyzed by UV-Vis spectrophotometry as shown in Table 3 indicated that the chosen model was significant ( $p>F$ less than 0.05). It was also known that the concentration of water glass was significantly affected by both variables, alkali hydroxide type, and alkali hydroxide concentration, and the interaction effect between alkaline and alkali concentration also given significant effect. Based on the interaction between these independent variables, the chosen model of ANOVA equation with actual factor are as follows for $\mathrm{NaOH}$ and $\mathrm{KOH}$ denoted by equation (1) and (2), respectively:

$\frac{1}{\text { concentration }}=+0.037-0.0021 *$ solvent concentration

$\frac{1}{\text { concentration }}=+0.0058+0.0075 *$ solvent concentration

The $\mathrm{R}^{2}$ value obtained from this model for $\mathrm{NaOH}$ was achieved 0.71 with a small difference with adjusted- $\mathrm{R}^{2}$ and predicted- $\mathrm{R}^{2}$ values, and an adequate precision value of 8.82 indicating the appropriate model. While for the model of $\mathrm{KOH}$ was achieved $\mathrm{R}^{2}$ value of 0.74 and an adequate precision value of 8.82 .

ANOVA results on water glass density response also released a significant model. The water glass density was significantly affected by the concentration of alkali hydroxide ( $p>$ F less than 0.05), but the alkali hydroxide type had no significant effect $(0.05<\mathrm{p}>\mathrm{F}<0.10$, where $\mathrm{p}$ $>\mathrm{F}$ of 0.085). The equation model of ANOVA including the interaction between the independent variables for the density of water glass with actual factor can be summed up in equation (3) and (4) which for alkali type of $\mathrm{NaOH}$ and $\mathrm{KOH}$, respectively. All this ANOVA analysis can be reported in Table 4.

Sqrt $($ density $)=+1.07+0.013 *$ solvent concentration 
Sqrt $($ density $)=+1.06+0.013 *$ solvent concentration

Where A was the coded factor for the alkaline type and $\mathrm{B}$ was the coded factor for the alkali concentration. The $\mathrm{R}^{2}$ value obtained from this model was 0.74 and existed a small difference with adjusted- $\mathrm{R}^{2}$ and predicted- $\mathrm{R}^{2}$ values, and an adequate precision value of 10.72 indicating the appropriate model.

Table 4. Analysis of variance (ANOVA) results on water glass density response

\begin{tabular}{|c|c|c|c|c|c|c|}
\hline Source & $\begin{array}{l}\text { Sum of } \\
\text { Squares }\end{array}$ & & $\begin{array}{l}\text { Mean } \\
\text { Square }\end{array}$ & $\begin{array}{l}\text { F- } \\
\text { value }\end{array}$ & $\begin{array}{l}\text { Prob > } \\
\text { F }\end{array}$ & Significance \\
\hline Model & 0.0039 & 2 & 0.0020 & 29.59 & $<0.0001$ & Significant \\
\hline Alkali type, A & 0.0002 & 1 & 0.0002 & 3.27 & 0.0848 & $\begin{array}{l}\text { Not } \\
\text { Significant }\end{array}$ \\
\hline $\begin{array}{l}\text { Concentration, } \\
\text { B }\end{array}$ & 0.0038 & 1 & 0.0038 & 55.91 & $<0.0001$ & Significant \\
\hline Lack of Fit & 0.0015 & 1 & 0.00002 & 0.22 & 0.6401 & $\begin{array}{l}\text { Not } \\
\text { Significant }\end{array}$ \\
\hline $\mathrm{R}^{2}$ & & & & 0.7381 & & \\
\hline Adjusted $\mathrm{R}^{2}$ & & & & 0.7132 & & \\
\hline Predicted $\mathrm{R}^{2}$ & & & & 0.6579 & & \\
\hline $\begin{array}{l}\text { Adequate } \\
\text { precision }\end{array}$ & & & & 10.723 & & \\
\hline
\end{tabular}

Lack of Fit (LOF) is a criterion for assessment of appropriate model in experimental results. The insignificant LOF values ( $\mathrm{p}>\mathrm{F}$ greater than 0.1 ) indicates the appropriate model for the experimental results [8]. Table 4 shows the LOF value for the equation model of density response was obtained 0.64 representing an appropriate model for density response. Furthermore, Table 5 concerns to declare average and deviation standard of an appropriate model, i.e. concentration model and density model with each response data.

Table 5. Error average and error deviation for each appropriate model

\begin{tabular}{ccc}
\hline $\begin{array}{c}\text { Alkali } \\
\text { Type }\end{array}$ & $\begin{array}{c}\text { Concentration- } \\
\text { response }\end{array}$ & $\begin{array}{c}\text { Density } \\
\text { Response }\end{array}$ \\
\hline $\mathrm{KOH}$ & $12.59 \% \pm 10.78 \%$ & $0.81 \% \pm 0.43 \%$ \\
$\mathrm{NaOH}$ & $10.24 \% \pm 6.73 \%$ & $1.46 \% \pm 0.83 \%$ \\
\hline
\end{tabular}

Based on ANOVA result, the alkali hydroxide type significantly affected the water glass concentration due to the difference of alkaline ion size which can affect the reactivity of the alkali ion in the reaction of water glass formation [9]. While the concentration of alkali hydroxide given an effect to the water glass concentration. There was a considerable relationship between the alkali concentration related to the number of $\mathrm{OH}$-ions that play an important role in the reaction mechanism between silica and alkali solution. The $\mathrm{OH}-$ ion will supply the imperfect form of the $\mathrm{SiO}_{2}$ tetrahedron, further the $\mathrm{OH}^{-}$ion will be released to form water and replaced by alkali ion [10] as follows in equation (5) [2], where $\mathrm{M}$ is denoted as a symbol for alkali metals.

$\mathrm{SiO}_{2}+{ }_{4} \mathrm{MOH} \rightarrow \mathrm{M}_{4} \mathrm{SiO}_{4}+2 \mathrm{H}_{2} \mathrm{O}$

The combination of interactions between $\mathrm{KOH}$ and low concentration of $\mathrm{M}^{-}$indicated good results for water glass concentrations due to the large reactivity of $\mathrm{K}^{+}$ions. Furthermore, the $\mathrm{OH}^{-}$ions became more easily released in fewer concentrations. According to previous research [2], too large $\mathrm{OH}^{-}$ion concentrations in alkali-silica reactions can induce the formation of an electric double layer. This double layer can be formed from the interaction between electrolyte solutions containing $\mathrm{OH}$-ions and the surface of a solid such as ultrasonic wave transmitter dipped in solution [8]. The existence of this electric double layer can prevent the reaction between bamboo leaf silica which not yet reacted with alkaline ions. However, the alkali type did not significantly affect the density of the water glass. It supposed that the water glass product attained a density of 1.218-1.352 gr/mL in accordance with the standard water glass density based on reference [10], i.e. in a range of 1.2-1.7 gr $/ \mathrm{mL}$. While the alkali concentration affected the water glass density since the alkali concentration is related to the number of molecules existing in a solution at a certain volume.

The optimum condition of the water glass product in this study was determined using numerical statistical analysis of software of Design Expert 8.0.6. The water glass produced under these optimum conditions were expected to have large concentrations with densities in a range of the commercial water glass density. The used alkali type achieved an optimum yield of potassium hydroxide at $4 \mathrm{M}$ releasing a water glass concentration of $41.08 \mathrm{~g} / \mathrm{L}$ and a density of $1.23 \mathrm{~g} / \mathrm{mL}$ with a desirability value of 0.547 .
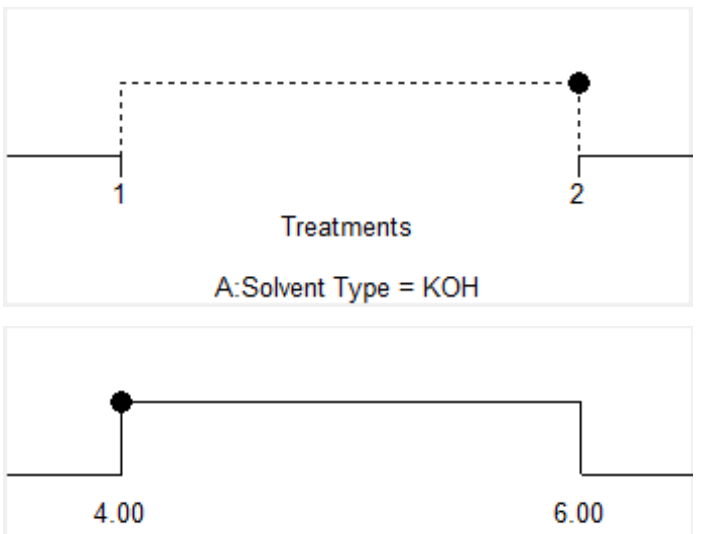

B: Solvent Concentration $=4.00$

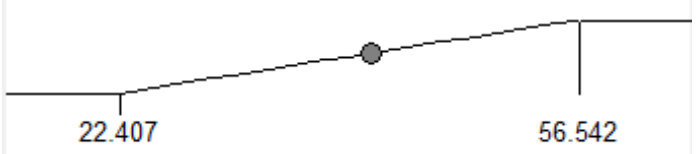

Concentration $=41.0845$

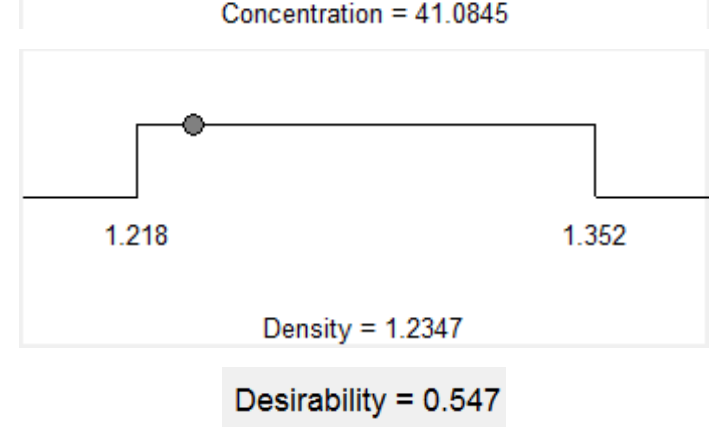

Figure 2. Ramp report of optimum condition for water glass product from bamboo leaf silica 
Fig. 2 reports the ramp of alkali type and alkali concentration under optimum conditions as well as the response of water glass concentration and density. This optimum condition can be obtained using potassium hydroxide $(\mathrm{KOH})$ because $\mathrm{KOH}$ is more reactive in the reaction of water glass formation resulted by larger $\mathrm{K}^{+}$ion size. It signified the distance between the atomic nucleus and outer shell electron is far enough to release the ion $\mathrm{OH}^{-}$[4]. The concentration of $4 \mathrm{M}$ was chosen as the optimum condition. It was considered this concentration did not form an electric double layer which can prevent the bamboo leaf silica reacting with the alkaline solution.

\subsection{Analysis of X-Ray Diffraction (XRD) on Bamboo Leaf Silica}

Silica ash $\left(\mathrm{SiO}_{2}\right)$ from petung bamboo leaf generated from the combustion process appeared in first color as grey. Therefore, it was necessary to purify to obtain white color of $\mathrm{SiO}_{2}$. Silica released out by optimum condition was dissolved in acid solution of $\mathrm{HCl}$ to purify the silica. The purified silica was then analyzed to acquire its material structure by using X-Ray Diffraction analysis as described in Fig. 3.

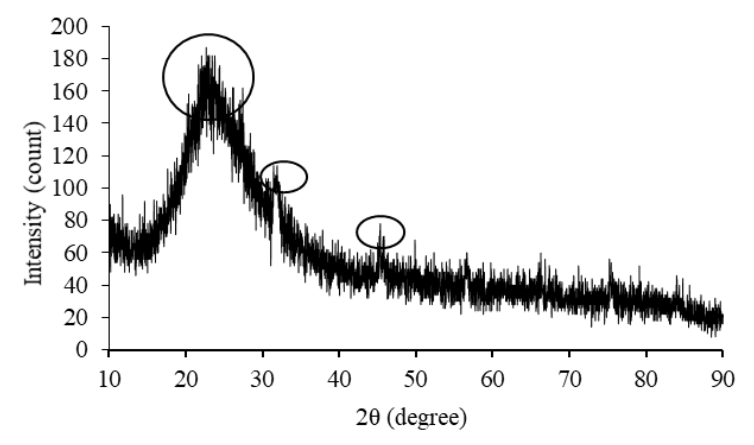

Figure 3. X-ray diffractions analysis (XRD) of purified $\mathrm{SiO}_{2}$ of petung bamboo leaf

Fig. 3 illustrates the XRD analysis on $\mathrm{SiO}_{2}$ of bamboo leaf observed the XRD patterns of $\mathrm{SiO}_{2}$ with the highest peak of $2 \theta$ at $22.64^{\circ}$ and an intensity of 182 counts, as indicated by black circles in Figure 2. This data in Fig. 3 suggest that it was not much different from previous studies [2, 5]. The high peak of $2 \ominus$ was attained at $23^{\circ}$ for $\mathrm{SiO}_{2}$. However, less of $\mathrm{ZnO}$ and $\mathrm{Al}_{2} \mathrm{O}_{3}$ still appeared in purified silica, i.e. $2 \ominus$ at $31.74^{\circ}$ and at $45.46^{\circ}$, respectively [11]. It can be inferred that the deviation of the peak resulted from heating to a temperature of $750^{\circ} \mathrm{C}$ during the burning of bamboo leaf [7]. Meanwhile, Fig. 3 shows the silica bamboo leaf having an amorphous structure and more diffraction peak of the crystalline structure of an oxide compounds.

\subsection{Scanning Electron Microscopy-Energy Dispersive X-ray (SEM - EDX) on Bamboo Leaf Silica}

The treated silica from bamboo leaf form optimum water glass has been investigated the elemental structure and quantitative information. Fig. 4 explains the composition of silica bamboo leaf consisted of Si element and $\mathrm{O}$ element. This figure also further visualized regards with the silica size after treated by $\mathrm{HCl}$ leaching and grounding by High Energy Milling (HEM) for $15 \mathrm{~min}$. The result also confirmed that there was still aggregation of the silica particle. Previous research of bamboo leaf silica-based to aerogel confirmed the average silica content based on EDX approximately $20.3 \%$ wt [5]. It was indicated that the silica content produced from water glass by $\mathrm{KOH}$ consisted of more than $40 \%$-wt.

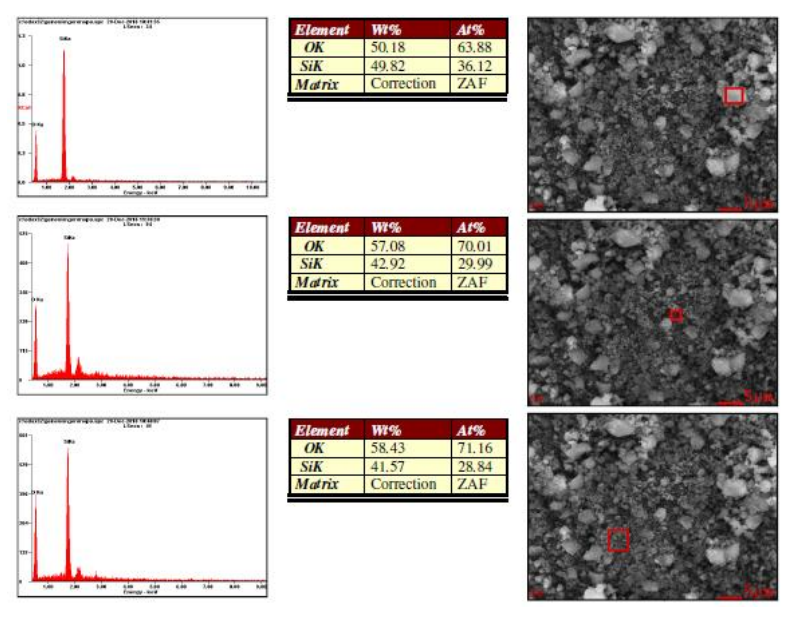

Figure 4. SEM-EDX analysis of purified $\mathrm{SiO}_{2}$ of petung bamboo leaf

\section{Conclusion}

The isolation of silica oxide from bamboo leaf have been investigated through acid leaching resulting 79.03\% by thermal process at $750^{\circ} \mathrm{C}$ and weight loss up to $20 \%$. The bamboo leaf silica from the leaching and thermal processes released a form with an amorphous structure. The ANOVA of the factorial design $2^{2}$ with six times of replications reported that the alkali concentration affected significantly on the concentration-response and the water glass density. The alkaline type also signified the effect on the water glass concentration, while it implied a few effects on the water glass density. The optimum condition of the water glass product can be obtained by potassium hydroxide $(\mathrm{KOH})$ with concentration of $4 \mathrm{M}$ producing a water glass with a concentration of $41.08 \mathrm{~g} / \mathrm{L}$ and density of $1.23 \mathrm{~g} / \mathrm{mL}$. However, the physical properties of silica produced with optimum water glass by $\mathrm{KOH}$ did not contrast with previous research of water glass by $\mathrm{NaOH}$.

\section{Acknowledgment}

The authors are grateful to the Advanced Material Laboratory (AMaL) co-workers of the Department of Chemical Engineering at Diponegoro University for support and facilities. The authors sincerely also thank Faculty of Engineering at Diponegoro University with research funding of No. 563/UN7.P/HK/2016, June 3, 2016.

\section{References}

[1] David C. Schuman, Ramon L. Carrasquillo, Josef Farbiarz, State-of-the Art Report on the Mechanism of Alkali-Aggregate Reaction in Concrete Containing Fly Ash, in, Center for Transportation Research, Bureau of Engineering Research, The University of Texas at Austin, Texas, 1988.

[2] Andy Chandra, Y.I.P. Arry Miryanti, Livia Budyanto Widjaja, Andika Pramudita, Isolasi dan Karakterisasi Silika dari Sekam Padi, in, Lembaga Penelitian dan Pengabdian kepada Masyarakat, Universitas Katolik Prahayangan, Bandung, 2012. 
[3] Agus Salim Purwanto, Taslimah Taslimah, Sriatun Sriatun, Sintesis dan Karakterisasi Silica Gel dari Tetraetilortosilikat (TEOS) Menggunakan Surfaktan Polyethylene Glycol (PEG) 6000 dalam Kondisi Basa, Jurnal Kimia Sains dan Aplikasi, 15, 1, (2012) 1-6

[4] J. R. Martínez, S. Palomares-Sánchez, G. OrtegaZarzosa, Facundo Ruiz, Yurii Chumakov, Rietveld refinement of amorphous $\mathrm{SiO}_{2}$ prepared via sol-gel method, Materials Letters, 60, 29, (2006) 3526-3529 https://doi.org/10.1016/j.matlet.2006.03.044

[5] Kien-Woh Kow, Rozita Yusoff, A. R. Abdul Aziz, E. C. Abdullah, From bamboo leaf to aerogel: Preparation of water glass as a precursor, Journal of NonCrystalline Solids, 386, (2014) 76-84 https://doi.org/10.1016/j.jnoncrysol.2013.11.041

[6] Moisés Frías, Holmer Savastano, Ernesto Villar, M. Isabel Sánchez de Rojas, Sergio Santos, Characterization and properties of blended cement matrices containing activated bamboo leaf wastes, Cement and Concrete Composites, 34, 9, (2012) 10191023 https://doi.org/10.1016/j.cemconcomp.2012.05.005

[7] Hua Xu, J. S. J. Van Deventer, The geopolymerisation of alumino-silicate minerals, International Journal of Mineral Processing, 59, 3, (2000) 247-266 https://doi.org/10.1016/S0301-7516(99)00074-5

[8] J. M. Paz-Garcia, B. Johannesson, L. M. Ottosen, A. B. Ribeiro, J. M. Rodriguez-Maroto, Modeling of Electric Double-Layers Including Chemical Reaction Effects, Electrochimica Acta, 150, (2014) 263-268 https://doi.org/10.1016/j.electacta.2014.10.056

[9] Samsudin Affandi, Heru Setyawan, Sugeng Winardi, Agus Purwanto, Ratna Balgis, A facile method for production of high-purity silica xerogels from bagasse ash, Advanced Powder Technology, 20, 5, (2009) 468-472 https://doi.org/10.1016/j.apt.2009.03.008

[10] U. Schlottmann, Soluble Silicate, SIDS Initial Assessment Report for SIAM 18, in, Bundesministerium fur Umwelt (BMU), Germany, 2004.

[11] S. Musi , N. Filipovi -Vincekovi , L. Sekovani Precipitation of amorphous $\mathrm{SiO} 2$ particles and their properties, Brazilian Journal of Chemical Engineering, 28, (2011) 89-94 http://dx.doi.org/10.1590/S0104$\underline{66322011000100011}$ 